\title{
Perancangan Fault Tolerant Control (FTC) pada Aplikasi Pengereman Regenerative Mobil Listrik dengan Model Half Car sebagai Anti-lock Braking System dengan Kesalahan Sensor
}

\author{
Dea Faiza Febrianty dan Katherin Indriawati \\ Departemen Teknik Fisika, Institut Teknologi Sepuluh Nopember (ITS) \\ e-mail: deafaizafebrianty@gmail.com
}

\begin{abstract}
Abstrak-Pada penilitian kali ini dilakukan perancangan Fault Tolerant Control yang diaplikasikan pada pengereman kendaraan listrik half car model, dengan motor bekerja secara regenerative sebagai anti-lock braking system, untuk mengkompensasi kesalahan yang ada pada sensor. Penelitian kali ini menggunakan kendaraan listrik dengan model half car sebagai plant. Terdapat 3 kontroler yang digunakan yaitu PI kontroler sebagai kontrol slip ratio yang mengatur agar slip ratio berada pada nilai 0,2 , PI kontroler sebagai kontrol putaran roda, dan hysteresis control. Motor yang digunakan adalah Brushless Direct Control yang berfungsi sebagai penggerak (aktuator) pada kendaraan. Pada penelitian ini menggunakan mode generator pada motor, sehingga motor dapat menyimpan energy yang dihasilkan ketika terjadi pengereman. Dengan kesalahan sensor yang diberikan pada roda depan kendaraan, maka digunakan observer untuk mengestimasi kesalahan kemudian kesalahan tersebut akan dikompensasi oleh Fault Tolerant Control. Dari perancangan yang dilakukan, FTC mampu mengestimasi kesalahan aktual dengan karakteristik respon yaitu maximum overshoot $9,765 \%$, rise time 0,00186 detik dan time settling 0,2954 detik. FTC juga mampu mengkompensasi kesalahan sensor berupa kesalahan bias hingga $50 \mathrm{rad} / \mathrm{s}$ dan kesalahan sensitivitas $\mathbf{7 5 \%}$.
\end{abstract}

Kata Kunci-Anti-Lock Braking System, Fault Tolerant Control, Pengereman Regenerative, Sensor.

\section{PENDAHULUAN}

$\mathrm{K}$ EBUTUHAN masyarakat pada alat transportasi yang aman dan nyaman, mendorong terus berkembangnya teknologi di bidang otomotif. Tingkat mobilisasi masyarakat yang tinggi menjadi alasan dibutuhkannya kendaraan yang aman dan nyaman. Kebutuhan mobilitas tersebut dipenuhi dengan perkembangan moda transportasi, khususnya mobil. Saat ini, masih banyak masyarakat yang menggunakan kendaraan dengan bahan bakar minyak atau fosil. Dengan adanya kebutuhan tersebut menyebabkan dampak yang serius seperti polusi udara, pemanasan udara, pemanasan global. Tingkat pencemaran udara di Indonesia semakin memprihatinkan. Bahkan menurut hasil survey yang dilakukan oleh World Bank, Indonesia menempati peringkat ke empat untuk negara dengan tingkat polusi tertinggi di dunia setelah Egypt, India dan China. Dari semua penyebab polusi udara yang ada, emisi transportasi terbukti sebagai penyumbang pencemeran udara tertinggi di Indonesia, yakni sekitar 85 persen [1].

Salah satu perkembangan terkait upaya meminimalisir dampak negatif dari mobil berbahan bakar fosil adalah dengan pembuatan mobil berbasis listrik, baik hybrid ataupun electric vehicle. Electric Vehicle (EV) berada di popularitas antara pertengahan abad ke-19 dan awal abad ke-20, ketika listrik merupakan salah satu metode yang disukai untuk menggerakkan mobil, memberikan kenyamanan dan kemudahan dalam beroperasi. Selama beberapa decade terakhir, meningkatnya kekhawatiran terhadap dampak lingkungan menyebabkan minat baru pada infrastuktur transportasi listrik [2].

Dalam mobil listrik ataupun mobil konvensional, terdapat beberapa sistem yang saling berhubungan satu sama lain. Salah satu sistem terpenting dalam mobil, baik listrik maupun konvensional adalah adalah sistem pengereman. Pengereman ini berfungsi untuk mengurangi kecepatan kendaraan. Apabila terjadi kegagalan pada pengereman akan menyebabkan kecelakan dan akan membahayakan pengguna mobil. Kegagalan yang sering terjadi pada pengereman adalah terkuncinya roda ketika kendaraan masih berjalan. Hal ini dikarenakan gaya yang diberikan pengereman yang diberikan pada roda terlalu besar. Untuk menghindari kegagalan tersebut maka diaplikasikan sebuah Anti-lock Braking System. Saat ini, ABS menjadi sebuah standar yang diharuskan untuk diaplikasikan pada kendaraan [3].

Ketika pengereman terjadi, sebagaian besar energi terbuang menjadi panas akibat gesekan antara kampas rem dengan roda. Permasalahan energi yang terbuang ini menjadi permasalahan penting terutama pada mobil listrik. Pengereman regenerative memungkinkan kendaraan listrik untuk menggunakan motor sebagai generator ketika rem diterapkan, untuk memompa energi kendaraan dari rem ke perangkat penyimpanan energi atau baterai. Pengereman regenerative adalah pendekatan yang efektif untuk memperpanjang rentang berjalannya Electric Vehicle dan dapat menghemat dari $8 \%$ hingga $25 \%$ dari total energi yang digunakan oleh kendaraan, tergantung pada siklus mengemudi dan bagaimana ia dikemudikan [2]. Oleh karena itu dibuat sebuah sistem regenerasi energi saat pengereman (Regenerative Braking System). 


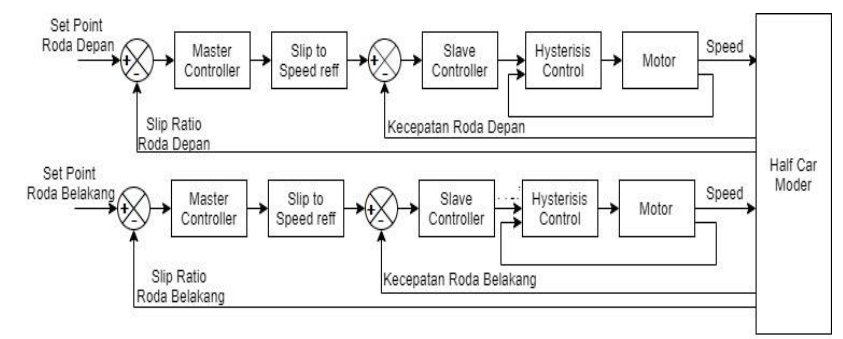

Gambar 1. Diagram Blok Pengendalian Sistem..

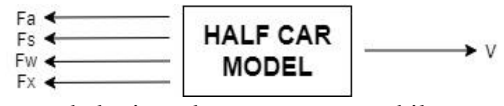

Gambar 2. Gaya yang bekerja pada pengereman mobil.

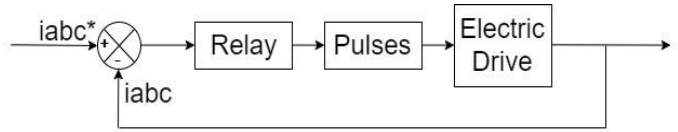

Gambar 3. Skema Hysteresis Control.

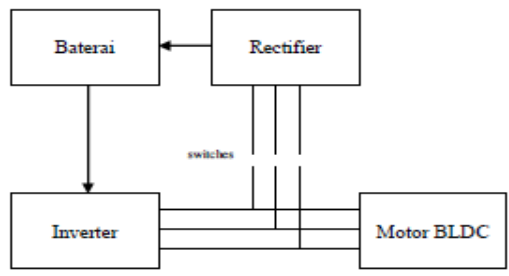

Gambar 4. Skema Motor.

Motor yang digunakan pada penelitian kali ini adalah Brushless Direct Current. Kelebihan dari motor BLDC memiliki efisiensi yang tinggi, rangke kecepatan yang lebih tinggi dan lebih sedikit noise [4]. Walaupun merupakan motor listrik synchronous AC 3 fasa, akan tetapi motor ini tetapi disebut BLDC karena implementasinya yang menggunakan sumber DC sebagai sumber utamanya yang kemudian diubah menjadi tegangan AC dengan menggunakan inverter 3 fasa [6].

Salah satu komponen terpenting dalam pengereman adalah sensor. Ketika sensor gagal atau terjadi kesalahan, maka sensor akan gagal membaca pembacaan pada roda dan akan menyebabkan kegagalan pada seluruh sistem, sehingga akan terjadi kecelakaan [5]. Untuk menghindari kejadian tersebut, maka dirancanglah sebuah sistem yang mampu mengkompensasi kesalahan yang ada pada sensor.

Oleh karenanya, tugas akhir ini dilakukan untuk merancang FTC pada sistem pengereman regenerative sebagai anti-lock braking system kendaraan listrik dengan kesalahan (fault) pada komponen sensor.

\section{METODE PENELITIAN}

Perancangan sistem dimulai dengan pemodelan half car terlebih dahulu kemudian dilanjutkan dengan pemodelan motor regenerative braking system. Apabila kendaraan telah mengalami pengereman, dan state of charge naik, maka dilanjutkan dengan pembuatan kontroler. Kontroler diaplikasikan pada tiap roda, dimana tiap roda terdapat 3 kontroler yaitu adalah master controller, slvae controller, dan hysteresis current control. Dan dilanjutkan dengan pemberian kesalahan pada sensor beserta observernya yang kemudian
Tabel 1.

Parameter gaya yang bekerja

\begin{tabular}{|c|c|c|}
\hline Parameter & Deskripsi & Nilai \\
\hline \multirow{4}{*}{$\begin{array}{l}A_{f} \\
c_{r}\end{array}$} & Massa mobil & $1298,9 \mathrm{~kg}$ \\
\hline & Luas area & $3.1 \mathrm{~m}^{2}$ \\
\hline & $\begin{array}{l}\text { Koefisien } \\
\text { aerodinamik }\end{array}$ & 0.3 \\
\hline & Koefisien resistansi putaran & 0.01 \\
\hline g & Gaya gravitasi & $9.8 \mathrm{~m} / \mathrm{s}^{2}$ \\
\hline$\delta$ & Densitas udara & $1.225 \mathrm{~kg} / \mathrm{m}^{3}$ \\
\hline $\mathrm{r}$ & Jari-jari roda & $0.325 \mathrm{~m}$ \\
\hline
\end{tabular}

Tabel 2.

Parameter koefisien gesekan pada aspal kering

\begin{tabular}{ll}
\hline \hline Parameter & Nilai \\
\hline $\mathrm{C}_{1}$ & 1,2801 \\
$\mathrm{C}_{2}$ & 23,99 \\
$\mathrm{C}_{3}$ & 0,52 \\
$\mathrm{C}_{4}$ & 0,3 \\
\hline \hline
\end{tabular}

Tabel 3.

Parameter Kontroler PI Cascade

\begin{tabular}{llll}
\hline \hline Roda & Kontroler & Parameter & Nilai \\
\hline \multirow{4}{*}{ Depan } & Master & P & 1.2 \\
& & I & 0.04 \\
& Slave & P & 0.3 \\
& & I & 2.3 \\
Belakang & Master & P & 1.2 \\
& & I & 0.04 \\
& Slave & P & 0.3 \\
\hline \hline
\end{tabular}

Tabel 4.

Perancangan Motor BLDC

\begin{tabular}{|c|c|c|}
\hline Parameter & Deskripsi & Nilai \\
\hline $\mathrm{J}$ & Inersia motor & $0,075 \mathrm{Kgm}^{2}$ \\
\hline$\beta$ & Koefisien redaman motor & $0,0003035 \mathrm{Nms}$ \\
\hline$K_{t}$ & Konstanta torsi & $0.57176 \mathrm{Nm} / \mathrm{A}$ \\
\hline $\mathrm{n}$ & Rasio Gearbox & 5 \\
\hline
\end{tabular}

kesalahan tersebut akan dikompensasi. Diagram blok pengendalian sistem dapat dilihat pada Gambar 1.

\section{A. Pemodelan Half Car Model}

Pemodelan half car model dilakukan dengan melihat persamaan-persamaan matematis yang ada ketika mobil sedang mengalami pengereman.Pemodelan ini adalah pemodelan gaya pengereman mobil hanya pada dau roda saja yaitu roda depan dan roda belakang. Gaya - gaya pengereman yang dimaksud ditunjukkan pada Gambar 2.

Peristiwa pengereman pada half car model sesuai dengan Hukum Newton II yang berbunyi "Jumlah vektro dari gayagaya yang berlaku pada sebuah objek adalah sama dengan massa dari objek tersebut dikalikan dengan akselerasi dari objek tersebut", dan ditunjukkan dengan persamaan (1)

$\Sigma F=m \cdot a$

$-2\left(F_{w}+F_{s}+F_{a}+F_{x}\right)=m \cdot \frac{d v}{d t}$

Dimana v merupakan kecepatan kendaraan, Fa merupakah gaya aerodinamis, Fs merupakan slope friction, Fw merupakan gaya resistansi putaran roda, dan Fx merupakan gaya gesek roda. Dengan nilai masing - masing gaya yaitu:

$$
\begin{aligned}
& F_{w}=c_{t} \cdot m \cdot g \cdot \cos \alpha \\
& F_{a}=0,5 \cdot c_{r} \cdot \delta \cdot A_{f} \cdot v^{2} \\
& F_{s}=m \cdot g \cdot \sin \alpha(2.5) \\
& F_{x}=\mu \cdot m \cdot g
\end{aligned}
$$




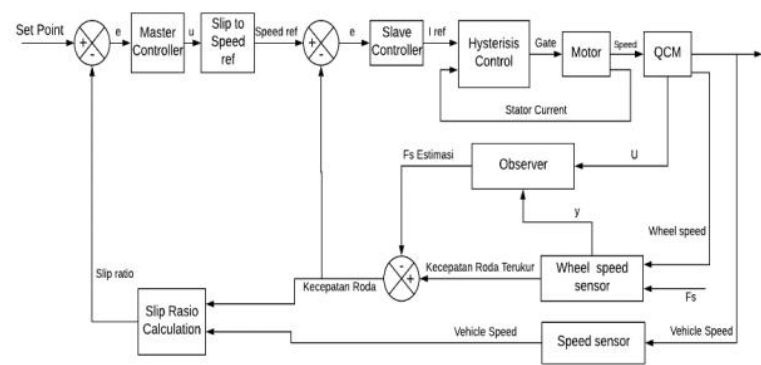

Gambar 5. Diagram Blok Sistem dengan Fault Tolerant Control.

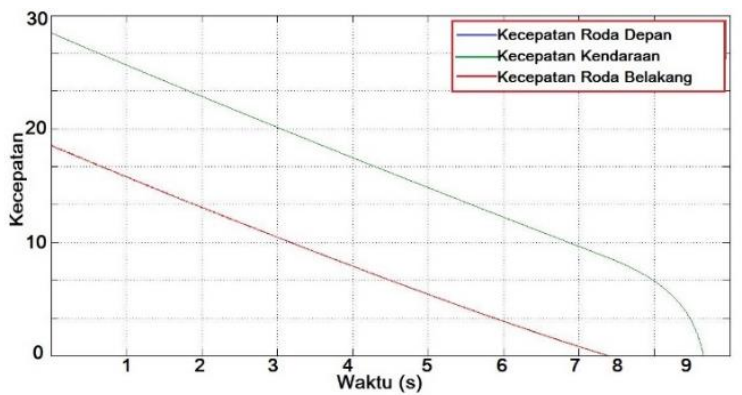

Gambar 6. Respon Kecepatan Kendaraan dan Roda saat Pengereman.

Dengan parameter yang digunakan dari pemodelan HCM ini dapat dilihat pada Tabel 1.

Nilai koefisien gesek $\mu$ didapatkan dari persamaan dibawah ini: $\mu(\lambda, v)=\left[C_{1}\left(1-e^{-C_{2} \lambda}\right)-C_{3} \lambda\right] e^{-C_{4} \lambda v}$

Dimana $\mathrm{v}$ merupakan kecepatan kendaraan. $\lambda$ merupakan nilai slip ratio, dan koefisien gesekan pada aspal kering yaitu nilai maksimum kurva gesekan $\mathrm{C}_{1}$, bentuk kurva gesekan $\mathrm{C}_{2}$, perbedaan antara kurva gesekan pada nilai maksimum dan pada saat lambda $\mathrm{C}_{3}$, dan nilai karakteristik kebasahan jalan $\mathrm{C}_{4}$ yang ditunjukkan pada Tabel 2.

Untuk melakukan kontrol anti-lock braking system, nilai slip ratio $\lambda$ yang akan digunakan adalah 0,2 . Slip ratio diperoleh dari persamaan berikut [9]:

$\lambda=\frac{v_{v}-R \cdot v_{w}}{v_{v}}$

Dimana Vv merupakan kecepatan linear kendaraan dan Vw merupakan kecepatan linear roda.

Dengan mensubtitusikan parameter yang ada kedalam persamaan gaya yang bekerja ketika pengereman kendaraan sehingga didapatkan persamaan:

$F_{w}=0,01 \cdot 1298,9 \cdot 98 \cdot \cos 0$

$F_{a}=0,5 \cdot 0,3 \cdot 1,2 \cdot 3,1 \cdot v^{2}$

$F_{x}=\mu .1298,9.9,8$

$F_{S}=1298,9 \cdot 9,8 \cdot \sin 0$

Permukaan jalan dianggap lurus sehingga nilai $\alpha$ dianggap 0 sehingga $F_{S}$ bernilai 0 .

\section{B. Pemodelan Motor}

Motor yang digunakan pada pemodelan ini adalah motor BLDC yang berfungsi sebagai penggerak dari kendaraan. Pemodelan motor dapat dikatakan valid apabila dapat melakukan pengereman pada kendaraan hingga kendaraan tersebut benar-benar berhenti dengan nilai slip ratio $\lambda=1$.

Pemodelan pada hysteresis control dilakukan dapat dilihat pada Gambar 3. Dimana iabc* merupakan arus referensi, iabc merupakan arus terukur. Dan output yang dihasilkan adalah

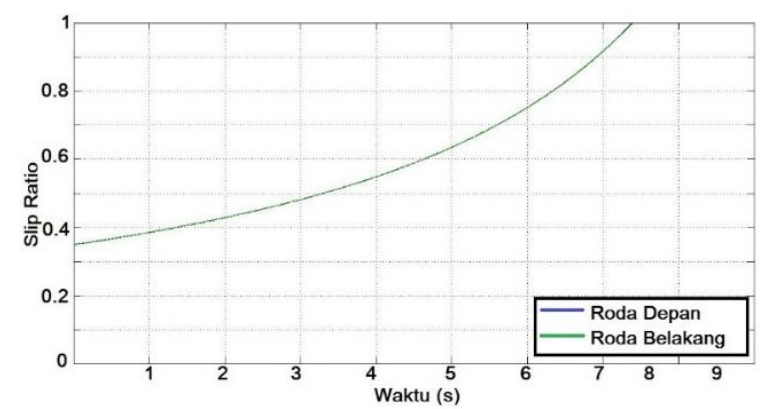

Gambar 7. Respon Slip Ratio saat Pengereman.

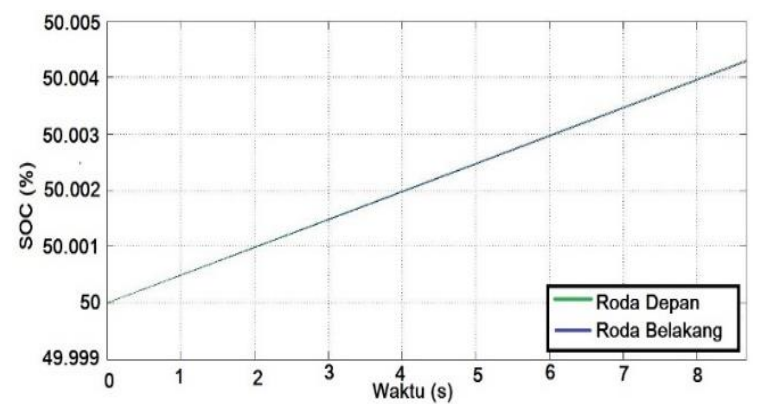

Gambar 8. Pengujian SoC dari Baterai.

sebuah 6 pulsa yang kemudikan dijadikan sebagai input inverter.

Pada sistem ini juga menggunakan pengereman regenerative, sehingga pada pemodelan motor ini dapat ditunjukkan melalui state of charge pada baterai yang memiliki penurunan lebih sedikit apabila dibandingkan dengan pengereman non-regenerative.

Pemodelan yang dilakukan terhadap motor yaitu Permanent Magnet Synchronous Motor, Inverter sebagai driver motor, rectifier, dan power supply berupa baterai. Baterai sebagai suplai utama pada motor mengirimkan daya kepada inverter. Inverter menerima masukan gate PWM dan akan mengalirkan sumber 3-fasa pada motor ketika mode motoring, atau mengalirkan daya kepada rectifier ketika mode generator sehingga dapat melakukan pengecasan pada baterai. Skema pemodelan motor dapat dilihat pada Gambar 3 [6].

Juga terdapat pemodelan wheel speed sensor yang berfungsi untuk mengukur kecepatan roda.Sensor yang digunakan diasumsikan memiliki respon orde 0 , sehingga memilik fungsi transfer dengan nilai penyebut dan pembilang adalah 1 . Respon orde 0 bersifat langsung yaitu semua input yang diterima sensor langsung diproses menjadi output saat itu juga. Dimana keluaran sensor merepresentasikan nilai kecepatan angular roda yang terukur. Skema motor dapat dilihat pada Gambar 4.

\section{Perancangan Kontroler}

Pada sistem pengereman regenerative sebagai anti-lock braking system ini menggunakan kontroler berupa PI cascade.

Master Controller berfungsi untuk mengatur slip ratio pada nilai 0,2 sehingga dapat menghasilkan gaya gesek yang maksimal seperti grafik yang ada. Selain itu juga terdapat Slave Controller yaitu kontrol kecepatan rpm untuk motor. Input dari kontrol slave ini adalah nilai selisih dari master kontrol sebagai rpm referensi dan output sensor sebagai feedback dari controller. Parameter-parameter pada control PID diperoleh dengan metode tuning [6]. Parameter yang digunakan untuk 
Tabel 5.

Performansi slave controller

\begin{tabular}{lll}
\hline \hline Roda & Karakteristik & Nilai \\
\hline Depan & Maximum Overshoot & $0,45 \%$ \\
& Rise Time & 0,0165 detik \\
& Settling Time & 0,1360 detik \\
Belakang & Maximum Overshoot & $0,36 \%$ \\
& Rise Time & 0,0165 detik \\
& Settling Time & 0,1360 detik \\
\hline \hline
\end{tabular}

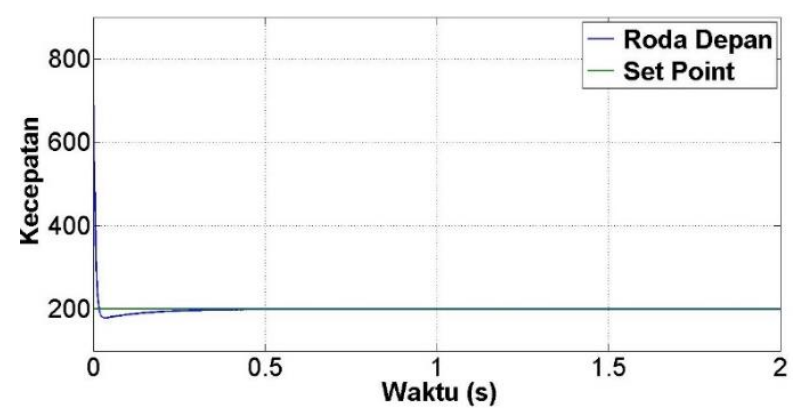

Gambar 9. Respon RPM Roda Depan pada slave controller.

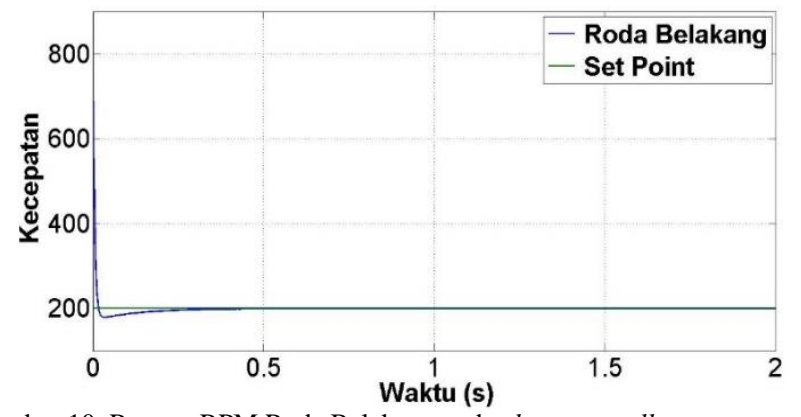

Gambar 10. Respon RPM Roda Belakang pada slave controller.

melakukan tuning pada controller dilakukan secara trial and error untuk mendapatkan hasil yang sesuai. Pada slave kontroler menggunakan set point berupa kecepatan motor saat pengereman normal yaitu $200 \mathrm{rpm}$ Kemudian master kontroler disambungkan dengan slave kontroler, set point yang digunakan untuk master kontroler adalah slip ratio 0,2 . Perancangan kontroler dikatakan valid apabila kontroler mampu mengatur PV agar sesuai dengan set point yang diberikan dengan performa yang baik. Parameter yang digunakan untuk controller tersebut adalah sebagai berikut:

\section{Perancangan Observer}

Perancangan observer dilakukan untuk mengesetimasi kesalahan yang diberikan pada sistem. Kesalahan yang digunakan kali ini yaitu kesalah yang ada pada sensor berupa kesalahan sensitifitas dan kesalahan bias. Pada perancangan observer menggunakan metode extended state observer untuk menentukan gain observer yang sesuai sehingga observer mampu untuk mengestimasi kesalahan yang diberikan.

Pada sistem ini, terdapat dua observer yang digunakan. Observer yang pertama berfungsi untuk mengestimasi gaya gesek $\left(F_{\mathrm{x}}\right)$, dikarenakan nilai $\mathrm{F}_{\mathrm{x}}$ juga mendapatkan efek dari kesalahan yang diberikan pada pembacaan kecepatan roda. Kemudian nilai $F_{x}$ yang dapat mengestimasi kesalahan digunakan sebagai input pada observer kedua yaitu mengestimasi kecepatan angular pada roda sehingga kesalahan yang terjadi dapat diketahui. Observer dikatakan valid apabila telah mampu mengestimasi kesalahan yang diberikan.
Tabel 6.

Performansi close loop sistem

\begin{tabular}{lll}
\hline \hline Roda & Karakteristik & Nilai \\
\hline Depan & Maximum Overshoot & $14,6 \%$ \\
& Rise Time & 0,00083 detik \\
& Settling Time & 0,3799 detik \\
Belakang & Maximum Overshoot & $14,6 \%$ \\
& Rise Time & 0,00083 detik \\
& Settling Time & 0,3799 detik \\
\hline \hline
\end{tabular}

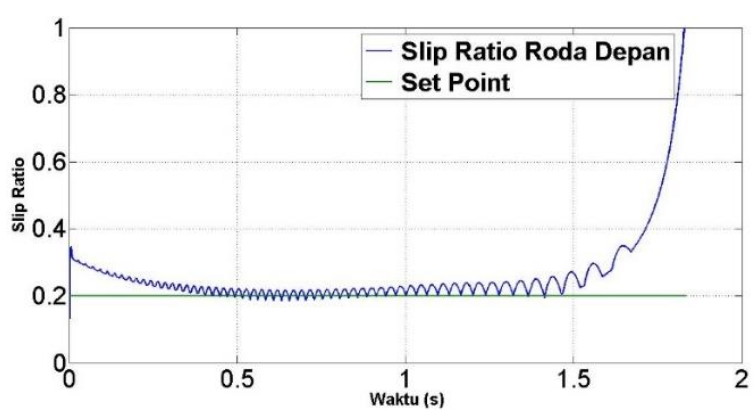

Gambar 11. Respon Slip Ratio Roda Depan Sistem Close Loop.

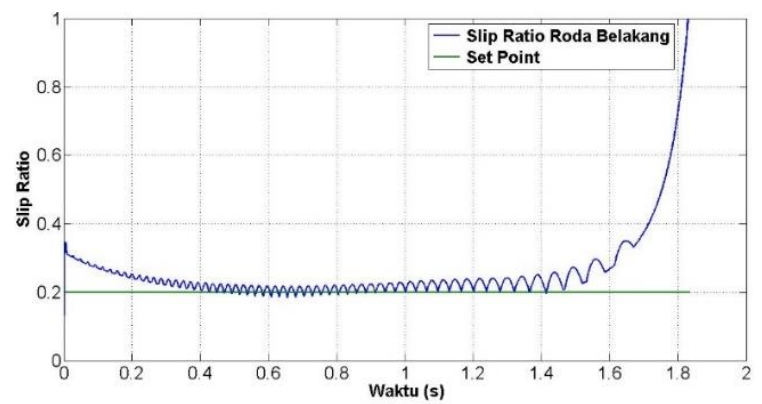

Gambar 12. Respon Slip Ratio Roda Belakang Sistem Close Loop.

Pada observer $F_{x}$ menggunakan persamaan (2) yang disubtitusikan dengan persamaan (9) hingga (11). Kemudian didapatkan persamaan sebagai berikut:

$\dot{v}=\frac{-2\left(F_{w}+F_{a}+F_{x}\right)}{m}$

Nilai $F_{w}, F_{a}, F_{x}$, dan $\mathrm{m}$ telah diketahui sehingga persamaan $\dot{v}$ menjadi

$\dot{v}=-\left(0,00154 . F_{w}+0,00154 \cdot F_{a}+0,00154 . F_{x}\right)$

Persamaan (14) dijadikan state space dengan matriks A berupa kesalahan yang akan diestimasi yaitu $F_{x}$, dan matriks $B$ berupa input yaitu $F_{a}$ dan $F_{w}$. Sehingga didapatkan matriks sebagai berikut:

$\dot{v}=[0] v+[-0,00154-0,00154]\left[\begin{array}{c}F_{a} \\ F_{w}\end{array}\right]+E_{1}$

Dengan $E_{1}$ adalah state kesalahan Fx yang mempunyai nilai $E_{1}=[-0,00154] F_{x}$

Nilai $F_{x}$ estimasi didapat dengan ekspansi matriks (15) menjadi bentuk

$\left[\begin{array}{c}\dot{v} \\ \dot{F_{x}}\end{array}\right]=\left[\begin{array}{cc}0 & -0,00154 \\ 0 & 0\end{array}\right]\left[\begin{array}{c}v \\ F_{x}\end{array}\right]+$
$\left[\begin{array}{cc}-0,00154 & -0,00154 \\ 0 & 0\end{array}\right]\left[\begin{array}{c}F_{a} \\ F_{w}\end{array}\right]+K . \hat{e}$

Observer $F_{x}$ diselesaikan menggunakan metode Linear Quadratic Regulator (LQR) [7] dengan menentukan gain yang sesuai. Nilai $\mathrm{R}$ dan $\mathrm{Q}$ didapatkan melalui metode trial and error hingga dapat menghasilkan respon observer yang optimal. Kali ini didapatkan nilai $\mathrm{R}$ dan $\mathrm{Q}$ yaitu:

$\mathrm{R}=0,001$ dan $\mathrm{Q}=\left[\begin{array}{cc}10^{3} & 0 \\ 0 & 10^{15}\end{array}\right]$ 
Tabel 7.

Performansi Observer ketika estimasi kesalahan

\begin{tabular}{ll}
\hline \hline Karakteristik & Nilai \\
\hline Maximum Overshoot & $9,765 \%$ \\
Rise Time & 0,00186 detik \\
Settling Time & 0,2954 detik \\
\hline \hline
\end{tabular}

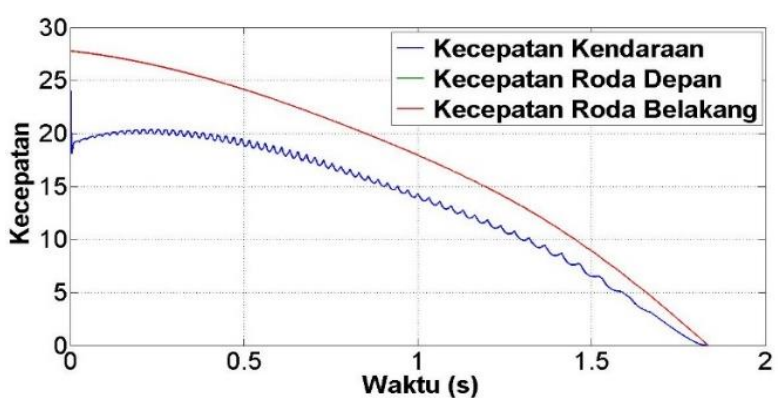

Gambar 13. Kecepatan Roda dan Mobil pada Sistem Close Loop.

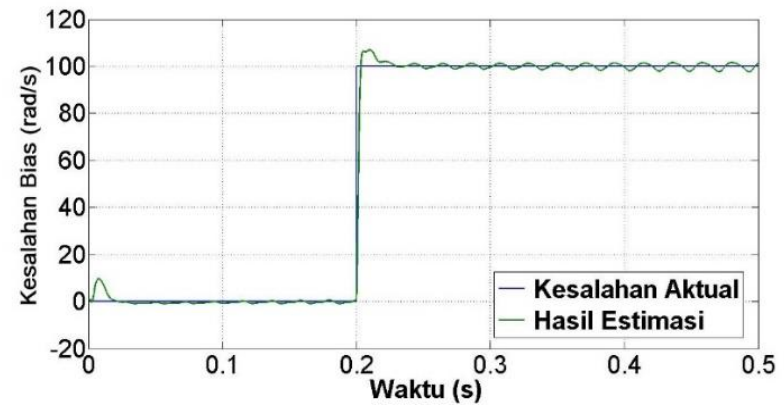

Gambar 14. Perbandingan Kesalahan Aktual dengan Kesalahan Estimasi Observer.

Nilai $\mathrm{R}$ dan $\mathrm{Q}$ akan menghasilkan gain $\mathrm{K}$ yang difungsikan sebagai gain Observer melalui fungsi matlab dan didapatkan nilai K sebagai berikut:

$K=\left[\begin{array}{ll}2 \times 10^{3} & -10^{9}\end{array}\right]$

Pada Observer $\omega$ menggunakan persamaan dinamika motor [10] yaitu:

$T_{e}-T_{l}=j \frac{d^{2} \theta_{m}}{d t^{2}}+\beta \frac{d \theta_{m}}{d t}$

Dengan $T_{e}$ merupakan torsi elektromekanik $(\mathrm{Nm}), \mathrm{T}_{1}$ merupakan torsi beban $(\mathrm{Nm}), \mathrm{j}$ merupakan inersia motor $\left(\mathrm{Kgm}^{2}\right), \beta$ merupakan koefisien redaman motor $(\mathrm{Nms})$, dan $\theta_{m}$ merupakan posisi sudut rotor (rad). Parameter motor yang digunakan dapat dilihat pada Tabel 4.

Torsi beban yang bekerja pada motor mempunyai nilai yang sebanding dengan besarnya torsi pada roda dan rasio dari gearbox, sehingga dapat dituliskan

$T_{l}=\frac{F_{x} \cdot r}{n}$

Dengan $\mathrm{n}$ merupakan rasio gearbox dan $\mathrm{r}$ merupakan jari-jari roda $(m)$.

Persamaan (18) disubtitusikan kedalam persamaan (17) dan dengan menggunakan parameter pada Tabel 4, maka didapatkan persamaan berikut:

$\dot{\omega}=-0,203 \omega-4,33 F_{x}+66,615 T_{e}$

Persamaan (19) diubah menjadi persamaan state space dengan kesalahan

$$
\begin{aligned}
& \dot{\omega}=[-0,0203] \omega+\left[\begin{array}{ll}
-4,33 & 66,615
\end{array}\right]\left[\begin{array}{l}
F_{x} \\
T_{e}
\end{array}\right] \\
& y=[1] \omega+\left[\begin{array}{ll}
-4,33 & 66,615
\end{array}\right]\left[\begin{array}{l}
F_{x} \\
T_{e}
\end{array}\right]+[1] F_{s}
\end{aligned}
$$

Tabel 8.

Hasil Respon Sistem dengan Kesalahan Bias pada Roda depan

\begin{tabular}{lll}
\hline \hline $\begin{array}{l}\text { Kesalahan } \\
\text { Bias (rad/s) }\end{array}$ & $\begin{array}{l}\text { Tanpa FTC } \\
\text { (Waktu Slip) }\end{array}$ & $\begin{array}{l}\text { FTC } \\
\text { (Waktu Slip) }\end{array}$ \\
\hline 1 & $\begin{array}{l}\text { Mengalami slip pada roda depan } \\
\text { dan belakang selama 0,3 detik. } \\
\text { Roda depan mengalami slip pada } \\
\text { detik ke 1,43. }\end{array}$ & $\begin{array}{l}\text { Kendaraan dan } \\
\text { roda depan } \\
\text { berhenti pada } \\
\text { detik ke 1,83 }\end{array}$ \\
10 & $\begin{array}{l}\text { Roda depan mengalami slip pada } \\
\text { detik ke 0,54. }\end{array}$ & $\begin{array}{l}\text { (Tidak terjadi } \\
\text { penguncian } \\
\text { roda). }\end{array}$ \\
25 & $\begin{array}{l}\text { Roda depan mengalami slip pada } \\
\text { detik ke 0,43 } \\
\text { Roda depan mengalami slip pada } \\
\text { detik ke } 0,42\end{array}$ & \\
50 & & \\
\hline \hline
\end{tabular}

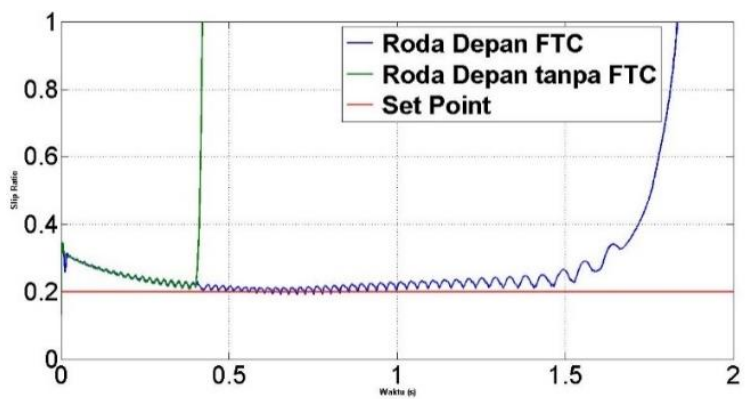

Gambar 15. Perbandingan Slip Ratio Roda Depan dengan dan tanpa FTC pada Kesalahan Bias $50 \mathrm{rad} / \mathrm{s}$.

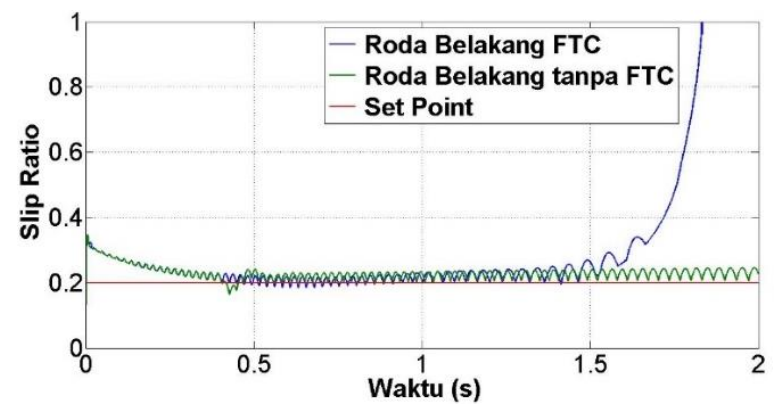

Gambar 16. Perbandingan Slip Ratio Roda Belakang dengan dan tanpa FTC pada Kesalahan Bias $50 \mathrm{rad} / \mathrm{s}$.

Dengan $F_{\mathrm{s}}$ merupakan kesalahan sensor yang diberikan. Kemudian bentuk state space diperluas dengan extended state space untuk memindahkan state kesalahan pada sensor [13] sehingga persamaan state space menjadi

$x_{a}=\left[\begin{array}{cc}-0,0203 & 0 \\ 1 & -1\end{array}\right]\left[\begin{array}{l}\omega \\ z\end{array}\right]+$

$\left[\begin{array}{cc}-4,33 & 66,615 \\ 0 & 0\end{array}\right]\left[\begin{array}{l}F_{x} \\ T_{e}\end{array}\right]+\left[\begin{array}{l}0 \\ 1\end{array}\right] E_{a}$

$y_{a}=z(t)=\left[\begin{array}{ll}0 & 1\end{array}\right]\left[\begin{array}{c}\omega \\ z\end{array}\right]$

Kemudian dirancang observer dengan estimasi kesalahan. Persamaan (20) dan (21) diekspansi sehingga didapatkan state space sebagai berikut:

$\dot{\hat{x}}=\left[\begin{array}{ccc}-0,02303 & 0 & 0 \\ 1 & -1 & 1 \\ 0 & 0 & 0\end{array}\right]\left[\begin{array}{l}\widehat{\omega} \\ \hat{z} \\ \widehat{f}_{s}\end{array}\right]+$

$\left[\begin{array}{cc}-4,33 & 66,615 \\ 0 & 0 \\ 0 & 0\end{array}\right]\left[\begin{array}{l}F_{x} \\ T_{e}\end{array}\right]+K_{e}$ 


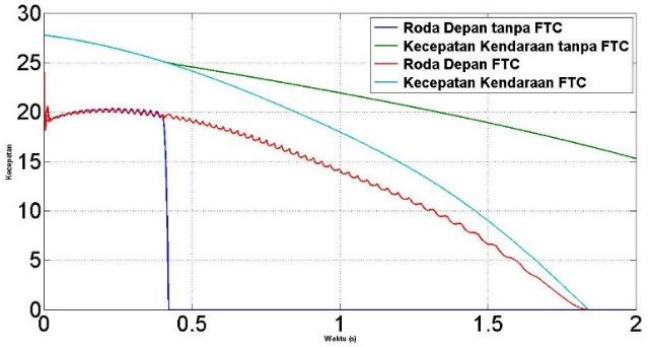

Gambar 17. Perbandingan Kecepatan Roda Depan dengan dan tanpa FTC pada Kesalahan Bias $50 \mathrm{rad} / \mathrm{s}$.

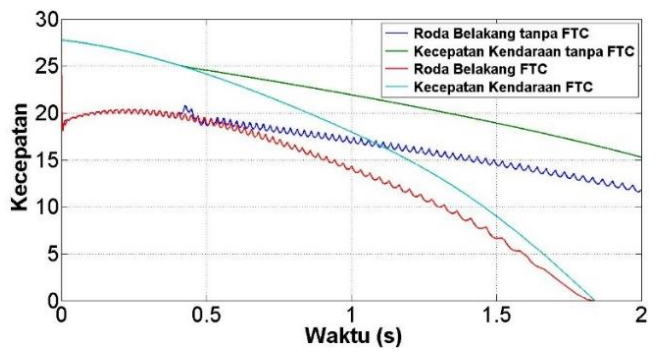

Gambar 18. Perbandingan Kecepatan Roda Belakang dengan dan tanpa FTC pada Kesalahan Bias $50 \mathrm{rad} / \mathrm{s}$.

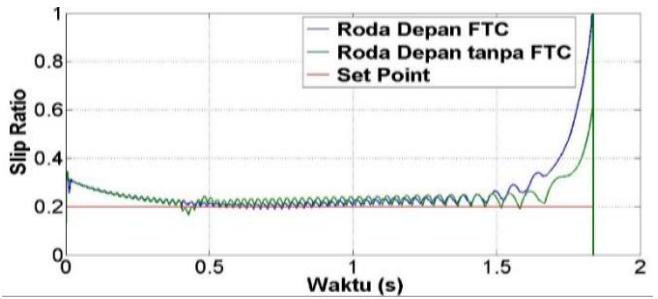

Gambar 19. Perbandingan Slip Ratio Roda Depan dengan dan tanpa FTC pada Kesalahan Sensitivitas 50\%.

$\hat{y}=\left[\begin{array}{lll}0 & 1 & 0\end{array}\right]\left[\begin{array}{l}\widehat{\omega} \\ \hat{z} \\ \hat{f}_{s}\end{array}\right]$

Atau dapat dituliskan

$$
\hat{A}=\left[\begin{array}{ccc}
-0,02303 & 0 & 0 \\
1 & -1 & 1 \\
0 & 0 & 0
\end{array}\right], \hat{B}=\left[\begin{array}{ccc}
-4,33 & 66,615 \\
0 & 0 \\
0 & 0
\end{array}\right],
$$

Observer $\omega$ juga diselesaikan menggunakan metode Linear Quadratic Regulator (LQR) dengan menentukan gain yang sesuai. Nilai R dan Q didapatkan melalui metode trial and error hingga dapat menghasilkan respon observer yang optimal. Kali ini didapatkan nilai $\mathrm{R}$ dan $\mathrm{Q}$ yaitu:

$\mathrm{R}=[0,1]$ dan $Q=\left[\begin{array}{ccc}1 & 0 & 0 \\ 0 & 10^{4} & 0 \\ 0 & 0 & 10^{11}\end{array}\right]$

Nilai $\mathrm{R}$ dan $\mathrm{Q}$ akan menghasilkan gain $\mathrm{K}$ yang difungsikan sebagai gain Observer melalui fungsi matlab dan didapatkan nilai $\mathrm{K}$ sebagai berikut:

$$
K=\left[\begin{array}{lll}
4,99 \times 10^{-6} & 1,45 \times 10^{3} & 10^{6}
\end{array}\right]
$$

\section{E. Perancangan Sistem Fault Tolerant Control (FTC) untuk Kesalahan pada Sensor}

Kesalahan yang telah berhasil diestimasi oleh observer akan dikompensasi oleh FTC. Dengan demikian, FTC akan mempertahankan sistem agar berjalan sesuai set point. Pada Gambar 5 dapat dilihat bahwa sinyal pembacaan sensor ditambahkan dengan nilai kesalahan yang telah terestimasi,

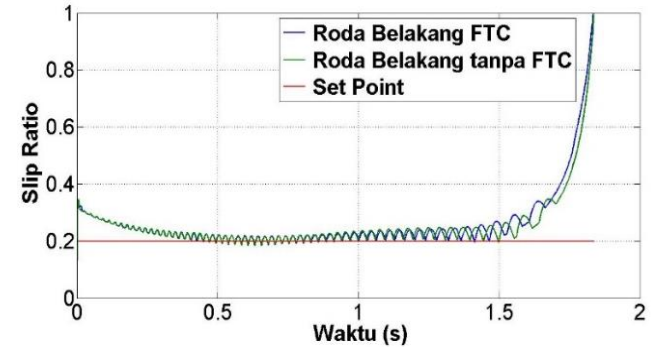

Gambar 20. Perbandingan Slip Ratio Roda Belakang dengan dan tanpa FTC pada Kesalahan Sensitivitas 50\%.

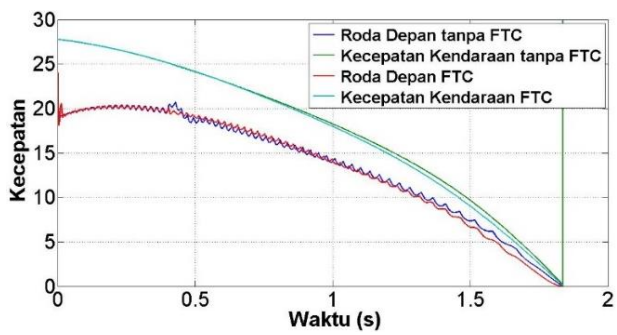

Gambar 21. Perbandingan Kecepatan Roda Depan dengan dan tanpa FTC pada Kesalahan Sensitivitas 50\%.

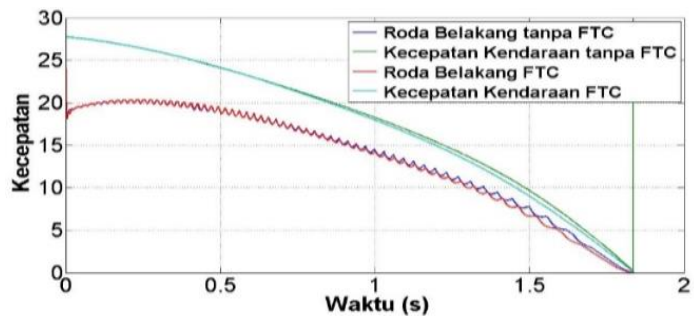

Gambar 22. Perbandingan Kecepatan Roda Belakang dengan dan tanpa FTC pada Kesalahan Sensitivitas 50\%.

sehingga menghasilkan kecepatan roda yang terukur atau dapat dilihat pada persamaan berikut:

$\omega_{\text {meas }}=\omega_{\text {aktual }}+\hat{f}_{s}$

Keluaran yang dihasilkan oleh observer yaitu berupa kesalahan yang terestimasi, kemudian keluaran sinyal pembacaan sensor dikurangi dengan nilai kesalahan yang telah terestimasi, dan menghasilkan nilai $\omega_{\text {est }}$ yang digunakan sebagai feedback pada slave kontroler, dan master kontroler berupa slip ratio.

Setelah dilakukan perancangan FTC, maka dilakukan pengujian yang bertujuan untuk mengetahui apakah sistem yang dirancang telah mampu mengkompensasi kesalahan yang diberikan pada sensor. Pengujian FTC dilakukan dengan memberikan kesalahan sensor berupa kesalahan bias dan kesalahan sensitivitas. Kesalahan tersebut disimulasikan pada roda depan saja dengan menambahkan sinyal bacaan dari sensor kecepatan roda pada waktu 0,4 detik. Kesalahan bias yang diuji sebesar $1 \mathrm{rad} / \mathrm{s}, 5 \mathrm{rad} / \mathrm{s}, 10 \mathrm{rad} / \mathrm{s}, 25 \mathrm{rad} / \mathrm{s}$, dan $50 \mathrm{rad} / \mathrm{s}$. Kesalahan sensitivitas yang diberikan sebesar 5\%, 10\%, 25\%, $50 \%$, dan $75 \%$.

\section{HASIL DAN PEMBAHASAN}

\section{A. Uji Pemodelan Regenerative Braking}

Dilakukan pengujian untuk pemodelan Regenerative Braking untuk memastikan apakah pemodelan tersebut telah 
merepresantikan sistem dengan baik. Hasil dari simulasi dapat dilihat pada Gambar 6 dan 7.

Gambar 6 menunjukkan bahwa model mampu melakukan pengereman dari kecepatan awal 27,78 m/s hingga berhenti. Kedua kecepatan roda berhenti pada detik ke 7,46 juga kecepatan kendaraan menurun dan berhenti pada detik 8,67. Perbedaan waktu berhenti antara roda dan kendaraan dapat diartikan bahwa terjadi slip atau terkuncinya roda, sehingga mobik akan sulit untuk dikendalikan. Gambar 7 menunjukkan nilai slip ratio yang terus naik dan mencapai nilai 1 pada detik ke 7,42 dan berhenti pada detik ke 8,67 yang menunjukkan terjadi terkuncinya roda.

Selain itu terdapat pengujian regenerative yang ditunjukkan dengan naiknya State of Charger (SOC) pada baterai yang dapat dilihat pada Gambar 8. Gambar 8 menunjukkan adanya kenaikan SOC yang bermula 50\% menjadi 50,0043\% hingga kendaraan berhenti.

\section{B. Uji Sistem Close Loop}

Pengujian kontroler dilakukan dengan uji close loop pada sistem. Kontroler digunakan untuk mengatur agar sistem berjalan sesuai dengan set point. Pada sistem ini menggunakan masing-masing 2 kontroler pada tiap roda. 2 kontroler tersebut disusun secara cascade, dengan master controller untuk mengendalikan slip ratio dan slave controller untuk mengendalikan kecepatan roda. Tuning pada kontroler dilakukan secara trial and error.

Kontroler yang pertama diuji ada slave kontroler dengan memberikan set point $200 \mathrm{rpm}$ yang merupakan rpm referensi. Hasil dari uji kontroler rpm dapat dilihat pada Gambar 9. dan Gambar 10. Respon dari sistem seperti ditunjukkan Gambar 9 dan Gambar 10 menunjukkan kontrol slave controller mampu mengendalikan kecepatan roda sesuai dengan set point yang diberikan. Parameter tuning yang dihasilkan pada kedua roda tersebut adalah $\mathrm{P}=0,3$ dan $\mathrm{I}=2,3$ dengan performansi respon dapat dilihat pada Tabel 5 .

Selanjutnya adalah pengujian pada kontroler slip ratio dengan memberikan nilai 0,2 sebagai set point. Parameter kontrol PI pada kedua roda didapatkan melalui metode trial and error dengan nilai $\mathrm{P}=1,2$ dan $\mathrm{I}=0,08$. Sehingga simulasi yang dilakukan memiliki respon seperti pada Gambar 11 dan 12.

Pada Gambar 11 dan 12 dapat dilihat bahwa controller telah mempu menjaga nilai slip ratio sesuai dengan set point dan menuju nilai 1 saat kendaraan berhenti. Performansi sistem ditunjukkan pada Tabel 6.

Dari Gambar 13 dapat dilihat bahwa kecepatan roda dan kecepatan kendaraan berhenti pada waktu yang sama yaitu 1,83 detik tanpa adanya roda yang terkunci dengan jarak pengereman 32 meter. Pada detik ke 0,1 roda mengalami penurunan yang drastic, akan tetapi dapat diatasi oleh ABS sehingga sistem mampu kembali ke slip ratio 0,2 sehingga kecepatan roda dapat mengikuti kecepatan kendaraan.

\section{Pengujian Observer}

Pengujian pada observer yang telah dirancang dirasa perlu untuk menentukan apakah nilai yang dihasilkan mampu mengestimasi nilai sebenarnya. Pengujian yang dilakukan adalah dengan memberikan kesalahan pada sensor roda depan. Kesalahan yang diberikan berupa fungsi step dengan nilai amplitude sebesar $100 \mathrm{rad} / \mathrm{s}$ pada detik ke 0,2. Hasil yang didapatkan dari pengujian observer ditunjukkan pada Gambar 14.

Gambar 14 menunjukkan bahwa ketika diberi kesalahan sensor, observer mampu mengestimasi kesalahan yang diterjadi di sensor. Hasil respon dapat dilihat pada Tabel 7 dan Tabel 8.

Dari performansi diatas dapat dilihat bahwa observer memiliki respon yang baik saat mengestimasi kesalahan.

\section{Pengujian Fault Tolerant Control dengan Kesalahan Bias}

Kesalahan bias adalah kesalahan pembacaan pada sensor yang menyimpang dari nilai aktualnya. Pengujian kesalahan bias dilakukan dengan menambahkan nilai step pada waktu ke 0,4 detik dengan nilai $1 \mathrm{rad} / \mathrm{s}, 5 \mathrm{rad} / \mathrm{s}, 10 \mathrm{rad} / \mathrm{s}, 25 \mathrm{rad} / \mathrm{s}$, dan 50 $\mathrm{rad} / \mathrm{s}$.

Gambar 15 hingga 18 menunjukkan respon slip ratio dan kecepatan sistem dengan FTC dan tanpa FTC ketika diberi kesalahan bias pada kesalahan tertinggi yaitu $50 \mathrm{rad} / \mathrm{s}$.

Sistem dengan FTC mampu mempertahankan kestabilannya setelah diberi kesalahan bias hingga $50 \mathrm{rad} / \mathrm{s}$ pada detik ke 0,4 . Dengan demikian, sistem dengan FTC mampu mengkompensasi kesalahan dan mengembalikan sistem menjadi seperti semula. Sedangkan sistem tanpa FTC sufah menunjukkan ketidakmampuan dalam mengatasi kesalahan sejak diberi kesalahan $5 \mathrm{rad} / \mathrm{s}$ dimana sistem mengalami kenaikan slip ratio atau penurunan kecepatan roda. Pada kesalahan bias $5 \mathrm{rad} / \mathrm{s}$ hingga $50 \mathrm{rad} / \mathrm{s}$, sistem mengalami penguncian roda.

\section{E.Pengujian Fault Tolerant Control dengan Kesalahan Sensitivitas}

Kesalahan sensitivitas merupakan kesalahan pada sensor dimana sensor mengalami kehilangan kepekaan sehingga tidak mampu untuk menerima perubahan yang terjadi. Nilai kesalahan sensitivitas yang diberikan pada pengujian ini yaitu sebesar 5\%, 10\%, 25\%, 50\%, dan 75\% pada detik ke 0,4.

Gambar 19 hingga 22 menunjukkan respon slip ratio pada sistem dan kecepatan pada sistem dengan FTC dan tanpa FTC ketika diberi kesalahan sensitivitas 50\%. Ketika kesalahan sensitivitas diberikan, sistem tanpa FTC tidak dapat membuat kendaraan berhenti dan terjadi lonjakan kecepatan ketika kendaraan berhenti.

Sistem dengan FTC mampu mempertahankan kestabilannya ketika sensor kehilangan sensitivitasnya hingga $75 \%$, dan sistem berjalan dengan optimal.

\section{KESIMPULAN}

Berdasarkan hasil pengujian dan analisa yang telah dilakuan, maka kesimpulan dari tugas adalah sebagai berikut:

1. Kesalahan sensor pada sistem ini akan mempengaruhi sinyal pembacaan yang dihasilkan oleh sensor sehingga torsi pengereman pun berbeda, dengan demikian nilai gaya gesek $F_{x}$ pun juga terpengaruhi. Kesalahan yang diberikan pada roda depan juga mempengaruhi putaran pada roda belakang.

2. Sistem regenerative sebagai anti-lock braking system pada mobil listrik yang dirancang ini mampu melakukan pengereman memiliki waktu pengereman 1,83 detik.

3. Sistem regenerative sebagai anti-lock braking system pada mobil listrik yang telah diberikan kesalahan sensor memiliki 
waktu pengereman melebihi 10 detik dan mengalami slip pada roda yang diberikan kesalahan..

4. Observer yang dirancang mampu merepresentasikan kesalahan actual yang terjadi dan memiliki parameter respon max overshoot $9,765 \%$, rise time 0,00186 detik, dan time settling 0,2954 detik dan error $12,75 \%$. Dilanjutkan dengan perancangan Fault Tolerant Control yang telah dirancang mampu mengompensasi kesalahan yang ada pada sensor baik kesalahan bias ( $1 \mathrm{rad} / \mathrm{s}, 5 \mathrm{rad} / \mathrm{s}, 10 \mathrm{rad} / \mathrm{s}, 25 \mathrm{rad} / \mathrm{s}$, dan $50 \mathrm{rad} / \mathrm{s})$ juga kesalahan sensitivitas $(5 \%, 10 \%, 25 \%, 50 \%$, dan $75 \%$.) dengan waktu pengereman 1,83 detik.

\section{DAFTAR PUSTAKA}

[1] A. Syaifulah, "Mobil Listrik 'ZEON' (Zero Pollution) Sebagai Sarana
Wisata di Ekowisata Mangrove Wonorejo," Progr. Kreat. Mhs., 2013.

[2] J. Varocky, "Benchmarking of Regenerative Braking for a Fully Electric Car," 2011.

[3] L. Jingang, "Performance Evaluation of an Anti-Lock Braking System for Electric Vehicles with a Fuzzy Sliding Mode Controller," Energies, vol. 7, pp. 6459-6476, 2014.

[4] Renesas Electronic Corporation, "What are Brushless DC motor," Renesas Electronic Corporation, 2019. [Online]. Available: https://www.renesas.com/us/en/support/technical-resources/engineerschool/brushless-dc-motor-01-overview.html. .

[5] Ying-Lan Yu, "Reserach of Sensor Fault-Tolerant Control Based on Analytical Reconstruction Model for Electronic Brake Pedal Simulator," Int. J. Model. Optimation, vol. 5, no. 6, 2015.

[6] K. Suganya, "Simulation of Four Four Quadrant Operation of Three Phase BLDC Motor Using Fuzzy," Int. J. Innov. Res. Sci. Eng. Technol., vol. 31, 2014.

[7] Araki M, "Pid Control." 